\title{
Developmental disabilities: Barriers in early identification
}

Mathew $\mathrm{R}^{1 *}$

*Corresponding author:

${ }^{1}$ Rincymol Mathew M.N, Assistant Professor, School of Behavioural Sciences, Mahatma Gandhi University, Kerala, India

Email: rincymg2012@gmail.com ORCID

\section{Information about the article:}

Received: Jan. 17, 2019

Accepted: Feb. 20, 2019

Published online: Dec. 27, 2019

\section{Publisher}

Nepal Health Research Society, Bahundhara -6, Gokarnesowor Municipality, Kathmandu, Nepal eISSN 2382-5545, ISSN 2676-1343 (Print)

(C) The Author(s). 2019

Content licensing: CC BY 4.0

\section{ABSTRACT}

\section{Background}

A healthy active child is a promise for healthy and productive future generation. But sometimes a baby is born with apparent defects or develop disturbances in intellectual, motor and social functioning in early childhood. This may be due to due to impaired development of the nervous system. It is estimated that in India $2.21 \%$ of the population is affected with disabilities out of which a major portion is contributed by disabilities of childhood origin. Developmental disabilities include limitations in function resulting from disorders of the developing nervous system. These limitations manifest during infancy or childhood as delays in reaching developmental milestones or lack of function in one or multiple domains including cognition, motor performance, vision, hearing and behavior. Early identification of the disabilities combined with initiation of appropriate medical, educational, social and psychological interventions can maximize the health outcome and minimize the impact of disability. This paper discusses the barriers identified in early intervention of developmental disabilities.

\section{Materials and methods}

Qualitative Sample: Parents of children affected with developmental disabilities, Primary School Teachers, Special Educators, Nursing personnel working in the clinical setting. Sample subjects were selected from local schools, and hospital by purposive sampling. Method of data collection: Focus group discussion. Instruments used: Self developed questionnaire to conduct discussion.

\section{Results}

The major themes evolved as the barriers in adoption of early intervention programmes were grouped under 7 categories namely intellectual, attitudinal, social, cultural, technological, political and economic barriers.

\section{Conclusion}

The study findings suggest direction regarding possible steps to facilitate enhancement of early intervention services by an exploration of the role played by different barriers.

\section{Keywords}

barriers, development, disability, early identification 